\title{
Tumour necrosis factor gene polymorphisms as severity markers in rheumatoid arthritis
}

\author{
Cornelis L Verweij
}

A large number of diseases are multifactorial whereby both environmental and genetic factors contribute to the aetiology and/or clinical severity. The genetics of many of these diseases is complex, involving multiple genes, and Mendelian patterns of inheritance do not apply. The genetic contribution in susceptibility for rheumatoid arthritis (RA) is exemplified by family clustering and a threefold to fourfold higher pairwise concordance percentage for clinically expressed RA in monozygotic twins than dizygotic twins. ${ }^{1-3}$ The mode of segregation in the population is best explained by a polygenic background influenced by the right environmental stimulus. Estimates suggest that at least 10 different genetic regions may be linked to susceptibility to RA. ${ }^{4}$ As a consequence, variability in the contribution of genetic factors involved in disease may be related to variability in clinical presentation with a spectrum ranging from mild to severe disease.

Good evidence exists that RA is associated with HLA-DRB1 alleles, in particular alleles that share a short amino acid sequence QKRAA, QRRAA or RRRAA at position 70-74 in the binding groove of the MHC molecule found in HLA-DR1 (HLA-DRB ${ }^{\star} 0101$ and 0102), DR4 (HLA-DRB1*0401, 0404, 0405), DR6 (HLA-DRB1*1402) and DR10 (HLADRB $\left.1^{\star} 1001\right)$ specificities named shared epitope (SE) alleles. ${ }^{5-7}$ Parametric linkage analysis suggests that HLA may contribute up to $30 \%$ of overall inherited susceptibility in RA. ${ }^{8}$ However, despite intense research efforts the functional basis of disease associated HLA alleles in RA is still not understood.

In the hunt for additional genetic factors that contribute to RA two approaches have been taken. Firstly, genome wide screening in large multicase family registries is carried out to define genetic regions that co-segregate with disease more frequently than is expected. Secondly, candidate genes may be defined on the basis of their role in the pathophysiology of the disease. Association studies in affected and unaffected persons are used to define disease susceptibility genes. Subsequent disease stratification studies may help to define genetic markers that are associated with specific clinical manifestations. As far as RA is concerned, these analyses may be complicated as a consequence of genetic heterogeneity, incomplete penetrance and gene interactions.

Leiden University Medical Centre, Department of Rheumatology, C4-R, PO box 9600, 2300 RC Leiden, the Netherlands

Correspondence to: Dr C L Verweij.
RA following the candidate gene approach. A large body of evidence indicated that polarised cytokine responses with as a consequence defi- ciencies or imbalances in the cytokine network may largely determine disease susceptibility and severity. Polarised cytokine profiles may not only play a part in immunopathological reactions but can also promote protection. In RA abundant expression of proinflammatory cytokines, such as TNF and interleukin 1 (IL1) are associated with pathology. In general TNF exerts either beneficial or deleterious effects, depending on the timing, localisation and extent of its release. Extensive research revealed that TNF is a pivotal factor in RA. ${ }^{9} \mathrm{Sev}-$ eral lines of evidence have contributed to assignment of a role for TNF in RA. The most compelling evidence stems from studies where remarkable clinical benefit was observed in RA patients treated with TNF blocking agents. ${ }^{10}$ Moreover, transgenic mice that overexpressed the human TNF gene developed a polyarthritis similar to RA. ${ }^{11}$

A critical question to be answered is which molecular mechanism underlies the difference in pro- and anti-inflammatory activity in inflammatory disease. Clinically useful information should come from understanding the molecular regulatory steps underlying the difference that would allow rapid identification of people who display a disturbed cytokine balance enabling clinicians to predict outcomes and to tailor treatment. The finding of interindividual differences in TNF production by peripheral blood mononuclear cells isolated from normal subjects towards a standard in vitro stimulus like endotoxin may provide a clue as to why patients produce inappropriate quantities of TNF ${ }^{12-15} \mathrm{To}$ estimate whether genetic influences were involved in the cytokine production profile we analysed TNF production profiles in whole blood cultures of monozygotic twins and siblings after stimulation with endotoxin for six hours. ${ }^{12}$ We observed an increased correlation for TNF production capacity in monozygotic twins compared with siblings. Approximately $60 \%$ of the variation in TNF production appear genetically determined. These data indicate a strong genetic influence on the production of cytokines upon ex vivo stimulation of whole blood with endotoxin and are in accordance with results from other investigators who reported genetic associations with HLA-DR alleles and other markers on chromosome $6 .^{13-15}$ These observations, together with the localisation of the TNF on chromosome 6 within the MHC class III region between HLA-B and HLA-DR genes, ${ }^{16}$ prompted speculation about the existence of functionally relevant polymorphisms in the TNF gene.

As a consequence the TNF gene has received considerable attention as a candidate disease associated gene in RA. 
Clinical relevance of genetically determined cytokine production profiles

To asses the genetic influence on cytokine production in relation to disease the heritability of the cytokine production capacity in relation to outcome of an infectious disease, in this case meningococcal infection, was analysed. ${ }^{12}$ Therefore, we studied the production of cytokines in first degree relatives of patients who either survived or died from meningococcal infection. A total of 190 first degree relatives of 61 patients with meningococcal disease of whom 45 survived and 16 died were studied. TNF production after six hours of stimulation with $100 \mathrm{ng} / \mathrm{ml}$ by whole blood of relatives of patients who died was only half of that in cultures of relatives from patients who survived. We also measured the production of the anti-inflammatory cytokine IL10 after 24 hours, which was twofold higher in whole blood of relatives of patients who died. When cytokine production within families was classified as low and high based on dichotomy around the median we observed that families with low TNF production had a 10-fold increased risk for fatal meningococcal disease. Families with high IL10 production had a 20 -fold increased risk for fatal disease. Families with both characteristics had the highest risk. From these data it is concluded that a genetically determined cytokine profile may contribute to disease outcome.

Based on the data it is proposed that a proinflammatory cytokine profile is important in the initial recovery phase of an infectious disease. This is in agreement with animal studies where an anti-inflammatory cytokine profile during the initial phase of infection dampens the nonspecific host response and allows growth of microorganisms. ${ }^{17}{ }^{18}$ Analogously, IL10 attenuates the clearance of various pathogens. Moreover, TNF receptor knock out mice are highly susceptible to infection. Whereas recombinant TNF can protect animals against lethal Gram negative bacterial sepsis. ${ }^{19}{ }^{20}$ For inflammatory autoimmune diseases the opposite is seen. Absence of IL10 leads to a chronic enterocolitis $^{21}$ and increased expression of TNF results in chronic arthritis. ${ }^{11}$ Thus the same profile may be beneficial in one condition and detrimental in another case depending on the clinical burden. Persons with an antiinflammatory cytokine profile may be less able to mount a robust immune response to eliminate the infectious agent and will develop fulminant disease. On the other hand a shift towards the pro-inflammatory side may underlie the pathology in polygenic diseases characterised by chronic inflammation and tissue destruction.

\section{TNF genetics and disease}

The search for heterogeneity within the TNF locus uncovered extensive polymorphism. Besides polymorphisms such as restriction fragment length polymorphisms (RFLPs), microsatellites and single nucleotide polymorphisms (SNPs) $^{22-26}$ in the regions outside the TNF gene a number of polymorphisms have been identified in the TNF gene itself. Until now we and others have identified a total of nine SNPs, one of which is located in the first intron at position +489 , one at position +70 in the 5 , untranslated region (UTR) and seven in the 5', regulatory region, a region involved in the regulation of TNF gene transcription (fig 1). ${ }^{27-33}$ The polymorphisms at position -238 and -376 were found to be in strong linkage

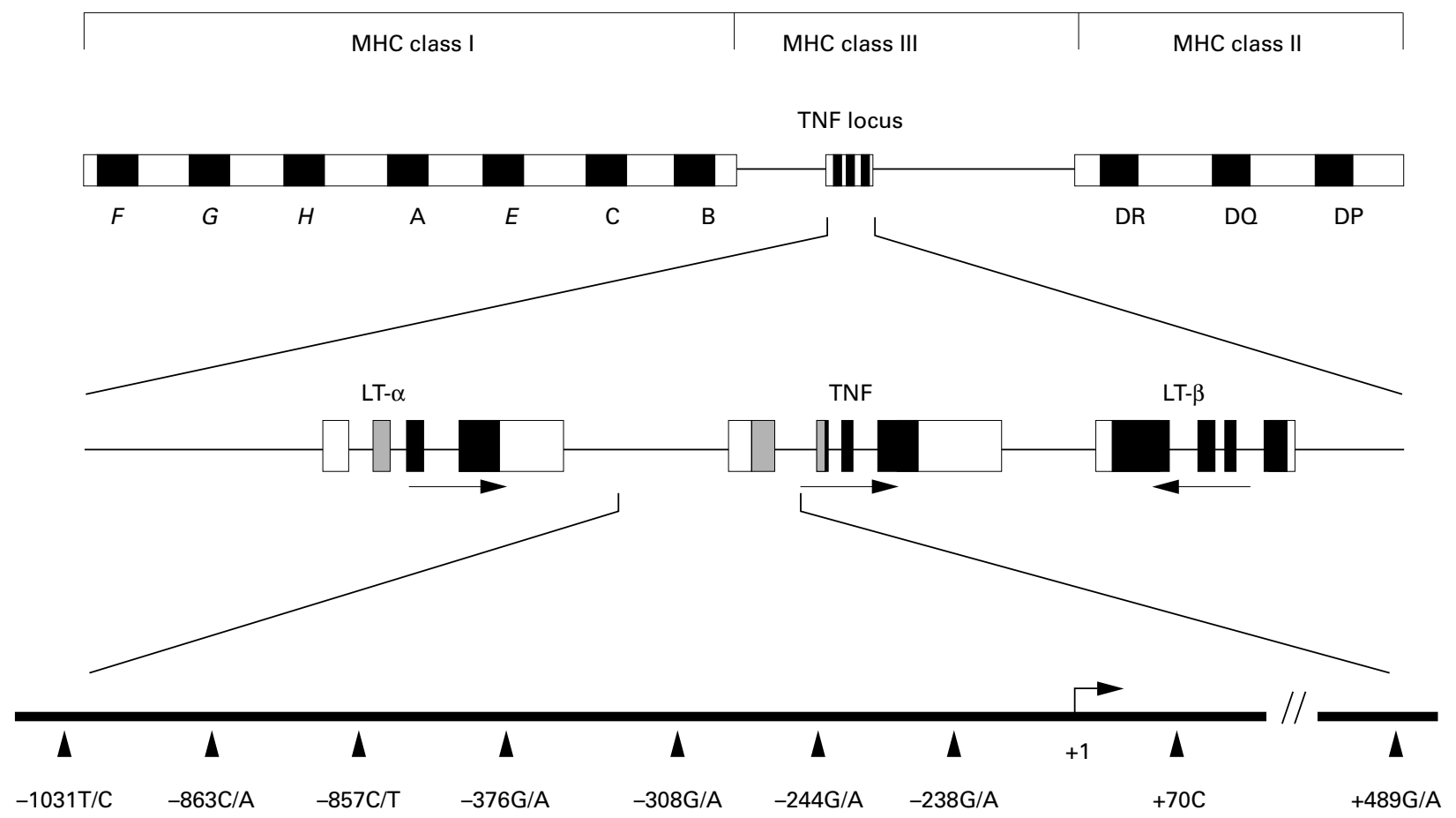

Figure 1 Schematic representation of the location of the TNF gene within the major histocompatibility complex. The middle row represents the intron/exon organisation of the TNF and LT genes. The arrows indicate the transcriptional orientation of the TNF and LT genes. At the bottom the 5'region of the gene including the transcription initiation site is depicted. The position of the SNPs within this part of the gene is indicated. 
disequilibrium. ${ }^{30}{ }^{34}$ The variants at position -238 and -308 revealed weak linkage. ${ }^{32}$ So far no polymorphisms have been identified in the 3 ' untranslated region that is involved in the regulation of translational efficiency and mRNA turnover. The TNF gene polymorphisms may be able to affect TNF production and, as a result, facilitate deregulation of the cytokine network, leading to pathology. Owing to the location of the TNF gene in the MHC, the existence of a disease causing allele may raise questions as to its role in rheumatic diseases in relation to class I and II alleles. This region of the genome is highly polymorphic and many of the diseases with an autoimmune component are associated with MHC alleles. Putative disease causing TNF alleles may either contribute independently of HLA class I and II alleles to disease, or constitute a joint risk factor with HLA class I and II alleles. Alternatively, as polymorphic genes within the MHC display a high degree of linkage disequilibrium, disease associations with MHC localised alleles could be a consequence of linkage with a nearby disease causing gene. An illustration of the latter point is the finding that the known MHC linkage of congenital adrenal hyperplasia was in fact attributable to the existence of MHC haplotype with a defective or absent 21-hydroxylase gene that is located within the class III region. ${ }^{35}$

The first polymorphism identified within the TNF gene is a $G$ to $A$ transition at position -308 relative to the transcription start site. The frequency of the uncommon allele in the white population is about $20 \%$. Most interestingly, the uncommon A allele is strongly associated with the HLA-A1-B8-DR3-DQ2 haplotype, ${ }^{27} 36$ which is associated with autoimmune diseases and the high TNF producer phenotype. ${ }^{13}$ Allele distribution studies in stratified patient groups revealed significant associations of this polymorphism with disease outcome in infectious diseases. The most significant findings have been in Malaria and Leishmaniasis. ${ }^{37}{ }^{38}$ It was estimated that TNF-308 A homozygotes have a relative risk of 4.0 to develop cerebral malaria and 7.7 for death or sequela. These associations were independent of HLA alleles and suggest that the TNF-308 allele could be a predisposing factor for cerebral malaria. Another disease associated with the TNF-308A allele is mucocutaneous Leishmaniasis. A significant increase of the -308 A allele was found in patients with the mucocutaneous form of Leishmaniasis, although the total number of patients studied was low.

Also for the -238 A polymorphism disease associations have been described. Hohler et a ${ }^{39}$ described a significant increase of the -238 GA genotype in patients with juvenile psiorasis and psioratic arthritis. For the +489 polymorphism an association with common variable immune deficiency is found ${ }^{40}$ The uncommon A allele was significantly increased in the granulomatous patients. This association was also independent of HLA.

In aggregate these data provide evidence that genetic variation within the TNF locus is important in disease susceptibility and outcome.

\section{TNF genetics and RA}

Analysis of the segregation of five TNF microsatellite markers with disease in 50 multicase RA families provided evidence for the presence of a susceptibility gene in or nearby the TNF locus independent of HLA-DRB $1 .{ }^{41}$ Results from another study of 61 white multicase RA families were in accordance with assignment of the TNF locus as an independent susceptibility locus. ${ }^{42}$ The segregation data further suggested that TNF microsatellite haplotypes, in particular a6b5c1d3e3, define an independent risk factor for RA. ${ }^{41}$ However, these findings were not confirmed by others who reported that the association of microsatellites with RA was secondary to HLA-DRB $1 .^{43}$

We investigated the association of TNF SNPs with susceptibility to and severity of RA in a group of 283 RA patients who visited the outpatient clinic. For analysis of an association with disease susceptibility we compared the distribution of $-376,-308,-238$ and +489 TNF alleles with that in a group of 130 healthy controls (table 1). This analysis showed a significant decrease of the +489 A allele in RA, suggesting a protective effect from this variant. ${ }^{44}$ The association was shown to be independent from the HLA-DRB1 SE alleles.

Next we determined the association of TNF genotypes and clinical parameters of disease heterogeneity. In a relatively large case-control study it was observed that the -238 GA and +489 GA genotypes were associated with less erosions during the first three years of disease. ${ }^{44}{ }^{45}$ This effect was independent of and interactive with the presence of HLA-DRB1 $\mathrm{SE}$ alleles. These findings were confirmed in a prospective study involving a cohort of RA patients wherein disease progression was monitored at study entry and after 3, 6 and 12 years. At each visit radiographs were taken of hands and feet. Joint space narrowing, erosions and malalignment of 12 feet and 34 hand joints were scored according to Sharp. The principal measure is the sum of erosions and narrowing

Table 1 Genotype and allele frequencies of the TNF gene polymorphisms in patients with $R A(n=283)$ and healthy controls

\begin{tabular}{|c|c|c|c|}
\hline \multirow[b]{2}{*}{ Genotype } & & \multicolumn{2}{|c|}{ Frequencies (\%) } \\
\hline & & $\begin{array}{l}R A \\
\text { patients }\end{array}$ & $\begin{array}{l}\text { Healthy } \\
\text { controls }\end{array}$ \\
\hline \multirow[t]{3}{*}{-376} & G/G & 99.3 & 97.8 \\
\hline & $\mathrm{G} / \mathrm{A}$ & 0.7 & 2.2 \\
\hline & $\mathrm{A} / \mathrm{A}$ & - & - \\
\hline \multirow[t]{3}{*}{-308} & $\mathrm{G} / \mathrm{G}$ & 69 & 57 \\
\hline & $\mathrm{G} / \mathrm{A}$ & 27 & 38 \\
\hline & $\mathrm{A} / \mathrm{A}$ & 4 & 4.5 \\
\hline \multirow[t]{3}{*}{-238} & G/G & 92.2 & 90.5 \\
\hline & G/A & 7.8 & 9.5 \\
\hline & $\mathrm{A} / \mathrm{A}$ & - & \\
\hline \multirow[t]{3}{*}{+70} & $-1-$ & 97.2 & 96.5 \\
\hline & $+\mathrm{C} /-$ & 2.8 & 3.5 \\
\hline & $+\mathrm{C} /+\mathrm{C}$ & & \\
\hline \multirow{3}{*}{$+489^{\star}$} & $\mathrm{G} / \mathrm{G}$ & 87.4 & 76.3 \\
\hline & $\mathrm{G} / \mathrm{A}$ & 11.6 & 23.7 \\
\hline \multirow{2}{*}{\multicolumn{4}{|c|}{ Alleles }} \\
\hline & & & \\
\hline-376 & A & 0.3 & 1.1 \\
\hline-308 & A & 18 & 23 \\
\hline-238 & A & 4 & 4.7 \\
\hline & $+\mathrm{C}$ & 1.4 & 1.8 \\
\hline$+489 \dagger$ & A & 7 & 12 \\
\hline
\end{tabular}

${ }^{\star} \mathrm{p}=0.003, \mathrm{pp}=0.01\left(\chi^{2}\right.$ test $)$. 
scores and ranges from 0 to 448 . This analysis showed a significant difference in the rate of joint damage, which was. 3.1 for the +489 GA patients versus 12.1 per year for the +489 GG patients (fig 2A). ${ }^{44}$ In analogy the rate of joint damage was decreased in the $-238 \mathrm{GA}$ versus -238 GG patients (fig $2 \mathrm{~B}$ )..$^{45}$ These data are in accordance with those of Criswell et $a l^{46}$ and Hajeer $e t a l^{43}$ who observed that TNF haplotypes defined by microsatellites were associated with the number of erosions in RA. In the aggregate, these results assign the TNF locus as a new genetic factor that contributes to disease activity in RA.

\section{Functional relevance of TNF gene polymorphisms}

As differences in disease outcome may result from dysregulation of inflammation, the association of TNF alleles with disease has strengthened the speculation on functionality
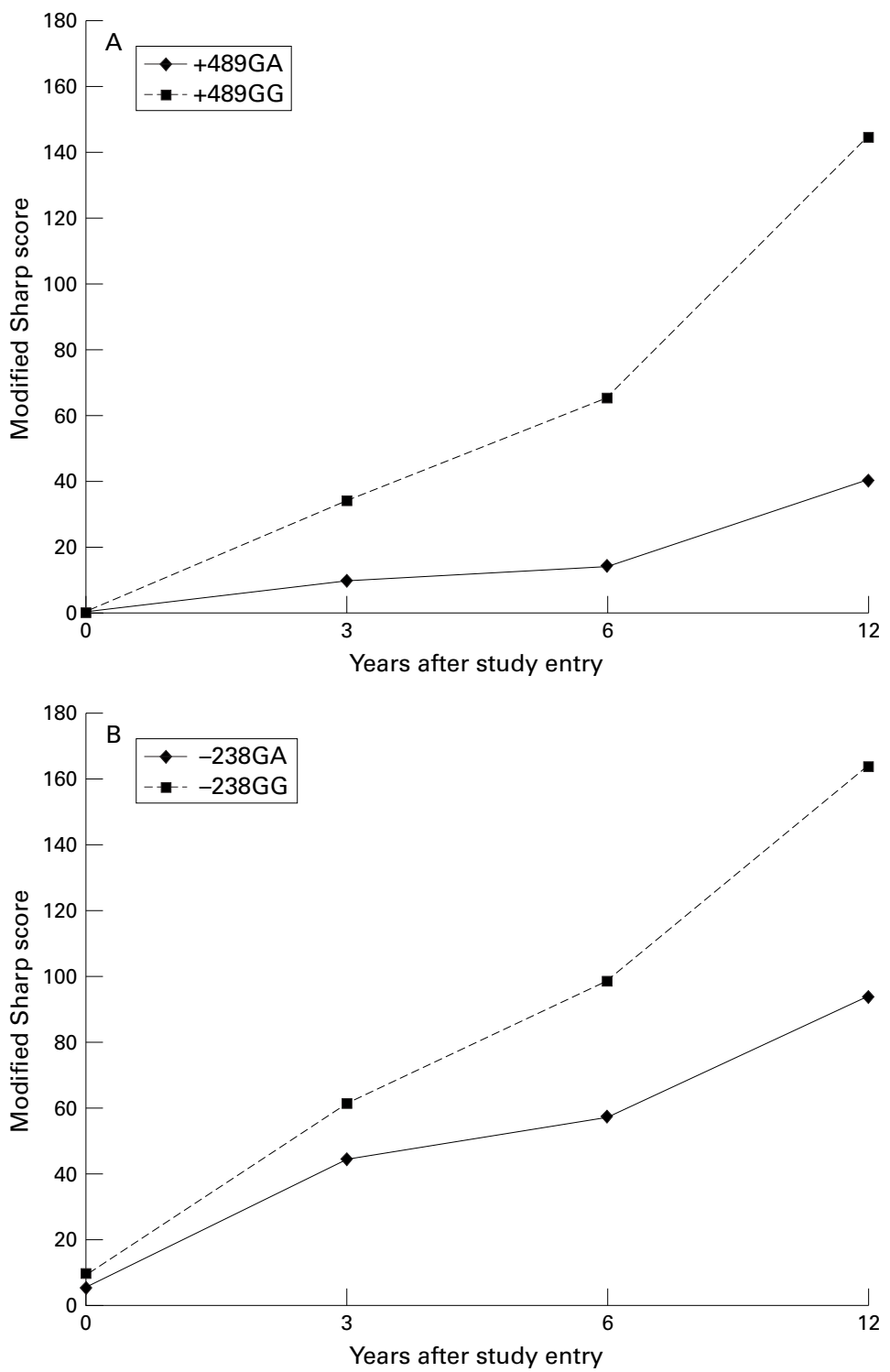

Figure 2 Foint damage in relation to the $T N F+489$ and -238 polymorphism in a prospective cohort of $R A$ patients. The median radiographic damage score expressed as modified Sharp score for radiographs of hands and feet for the TNF $+489 G G$ and $G A$ patients (panel $A$ ) and the TNF-238 GG and $G A$ patients (panel B) is presented. Modified Sharp scores at onset $(t=0)$, at 3,6 and 12 years is depicted. of TNF gene polymorphisms. Therefore, we studied whether the nucleotide substitutions had a direct effect on the amount of TNF produced, in particular by interference at the level of TNF gene transcription. Comparison of the sequence encompassing the -308 position revealed no similarity with known functional protein binding DNA sequences. To discover if this sequence has protein binding activity we performed gel retardation analysis with oligonucleotides encompassing the -308 position containing either a $\mathrm{G}$ or an $\mathrm{A}$ at that position in combination with nuclear extract from unstimulated and stimulated Jurkat cells, U 937 cells and Mono Mac 6 cells. This analysis revealed protein binding potential of the sequences, although no gross alterations in protein binding could be observed between the allelic oligonucleotides (Bayley JP, Kaijzel EL, Breedveld FC, Verweij CL, unpublished observations). To examine whether the protein binding capacity of the -308 sequence was of functional relevance for the transcriptional activity of the TNF promoter we generated promoter constructs wherein a $10 \mathrm{bp}$ sequence encompassing the -308 position was replaced by a random sequence. A total of three constructs were generated that carried substitutions from -303 to $-313,-300$ to -310 and -306 to -316 . These mutant promoters were linked to the Luciferase reportergene and transfected in Jurkat cells. Analysis of reportergene expression as measure of promoter activity showed no significant difference in the mutants compared with the wild type promoter indicative that this region is not of relevance in TNF promoter activity in response to standard in vitro. Next we determined whether the $G$ to A transition at position -308 would influence the promoter activity (fig 3). Promoter/ reportergene constructs containing the $-308 \mathrm{~A}$ and $\mathrm{G}$ allelic promoters in the absence or presence of the TNF 3'UTR were used. Transfection studies in Jurkat cells either unstimulated or stimulated with different reagents showed no difference in promoter activity between $G$ and $\mathrm{A}$ promoter alleles. A similar conclusion was reached when using Raji B cells. ${ }^{47}$ As it could be argued that functional studies in cell lines are not representative for the physiological situation we developed a method to compare differences in allelic TNF mRNA expression in primary cells. This method is based on variation at position +70 in the 5'UTR of the TNF gene. ${ }^{29}$ As this variant is expressed in the mRNA it allows us to quantitatively discriminate between the allelic transcripts in a heterozygous person. For this analysis we selected people who were heterozygous for both the +70 polymorphism and the -308 polymorphism. One person has the -308 A position linked to the $\mathrm{C}$-insertion at position +70 whereas in the other person this polymorphism is linked to the $-308 \mathrm{G}$ allele. PBMC were isolated and stimulated in vitro with LPS to stimulate monocytes or anti-CD3/CD28 to stimulate T cells. RNA was harvested and RTPCR analysis on TNF mRNA was performed. Relative quantitation of the respective allelic TNF RT-PCR products based on the nucle- 
otide difference in length, revealed no significant difference between the two alleles, indicative that both the $-308 \mathrm{~A}$ and $-308 \mathrm{G}$ allele contribute equally to the total TNF mRNA pool. Similar results were obtained with synovial tissue where TNF mRNA is expressed under physiological conditions. ${ }^{47} 48$ These data confirm our earlier observations that the -308 G to A transition does not appear to have an effect on gene transcription.

Despite a lack of evidence for functional significance of $-308 \mathrm{G}$ to $\mathrm{A}$ transition in at least three independent studies ${ }^{31} 4749$ others reported on functional relevance for this polymorphism..$^{50-52}$ Wilson et al reported on a sixfold to sevenfold increase of the -308 A allele in unstimulated Raji cells, ${ }^{50}$ whereas Kroeger et al found a twofold increase in Jurkat cells only in combination with the 3'UTR present in the reportergene construct. ${ }^{51}$ As consensus in this field is absent we feel further studies are needed to make conclusive statements on the functional relevance of the TNF $-308 \mathrm{G}$ to A transition.

We also tested the functional relevance of the -238 polymorphism in promoter/reportergene studies (fig 3). These analyses revealed no significant difference between the allelic promoters in unstimulated and stimulated Jurkat $\mathrm{T}$ cells, Raji B cells and U937 and MonoMac6 cells. ${ }^{34}$

Moreover, we tested the +489 polymorphism for functional relevance (fig 4). This polymorphism is located in the first intron of the gene and allowed us to discriminate between the allelic TNF precursor mRNA products. As the presence of the $G$ allele provides a Tail restriction site whereas the A allele is not cleaved by TaiI we could distinguish the respective TNF RT-PCR products by RFLP. PBMC were isolated and stimulated with LPS. TNF precursor mRNA was amplified by RT-PCR and digested with TaiI. The upper band is representative for the undigested A allelic transcript and the lower band for the cleavable $G$ transcript. The ratio between these band varies between 1.1 and 1.4. The slight overrepresentation of the uncleavable A product is attributable to some heteroduplexformation in the PCR. Hence, the result is indicative that the same amount of precursor mRNA is produced from the respective TNF alleles, which conclusion excludes a difference in TNF gene transcription between the $+489 \mathrm{~A}$ and $\mathrm{G}$ alleles.

Thus the disease associations may have to be explained by linkage disequilibrium with alleles within or nearby the TNF/LT locus. Interestingly, preliminary data suggest linkage of the $+489 \mathrm{G}$ allele with the TNF a6 microsatellite. This might suggest that +489 A is part of a haplotype that is associated with less severe disease in RA.

\section{Concluding remarks}

The data indicate the existence of TNF gene variants as novel markers for disease severity in

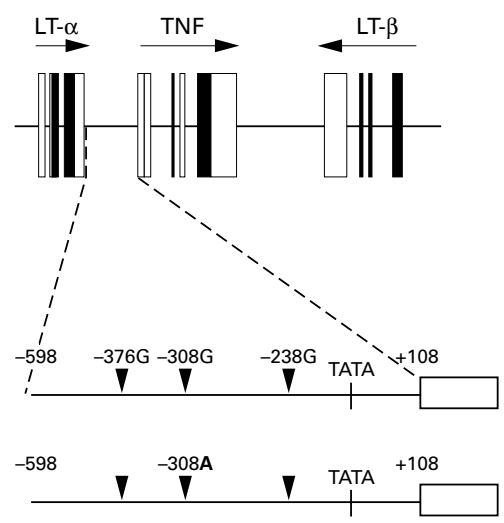

Jurkat

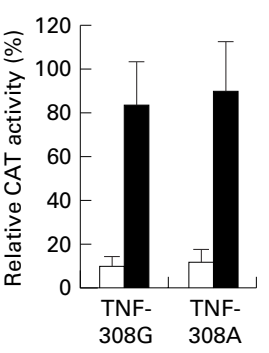

Raji

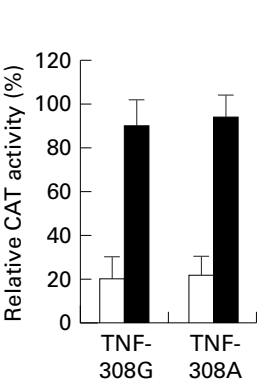

U937

Mono Mac 6
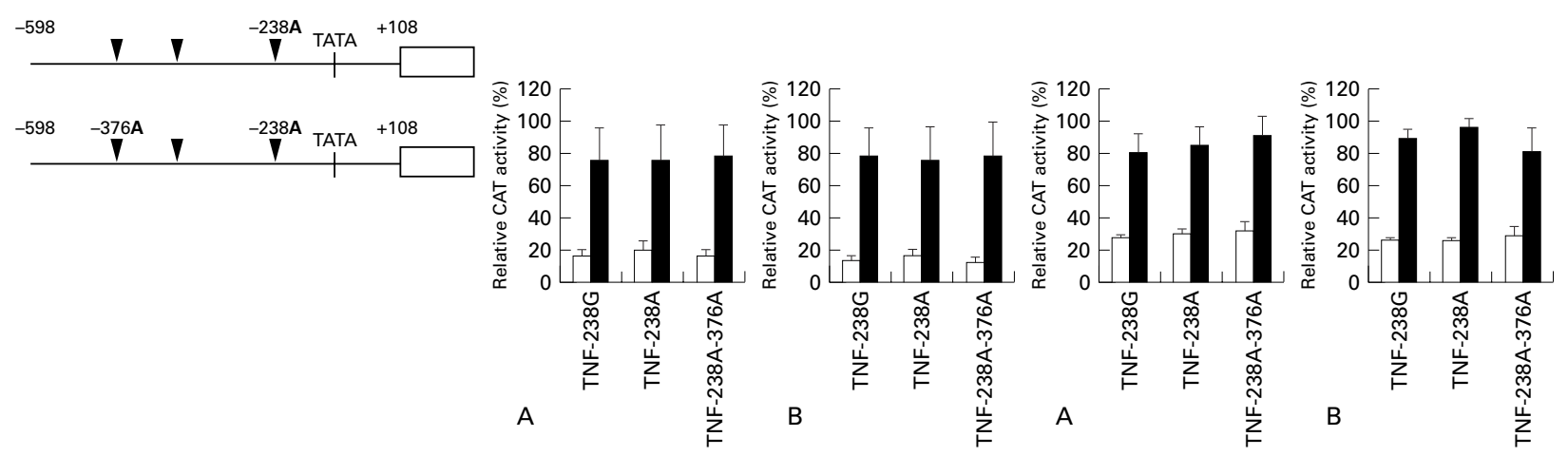

ND

ND

Figure 3 Schematic representation of the human TNF locus and the TNF promoter/reportergene constructs used to study the functional relevance of the $-376,-308$ and -238 gene variants. In the right panel the results of the transfections are shown. Presented are the results from at least three independent transfections with three different batches of DNA. Reportergene expression is expressed as the relative activity of the plasmid with the highest activity $(100 \%)$ reached at after stimulation in each experiment. Relative reportergene expression levels were averaged (SD) and plotted in histograms. Furkat cells were unstimulated (open bars) or stimulated for 24 hours with anti-CD3 $(0.5 \mu \mathrm{g} / \mathrm{ml})$ and anti-CD28 $(5 \mu \mathrm{g} / \mathrm{ml})$ (filled bars). Raji cells were unstimulated (open bars) or stimulated for 24 hours with PMA (50 ng/ml) filled bars. U937 and Mono Mac 6 were unstimulated (open bars) or stimulated (filled bars) for four hours with LPS (1 $\mu \mathrm{g} / \mathrm{ml}) / P M A(10 \mathrm{ng} / \mathrm{ml})$ and $L P S$, respectively. $\mathrm{ND}=$ not determined. 
TNF +489 A

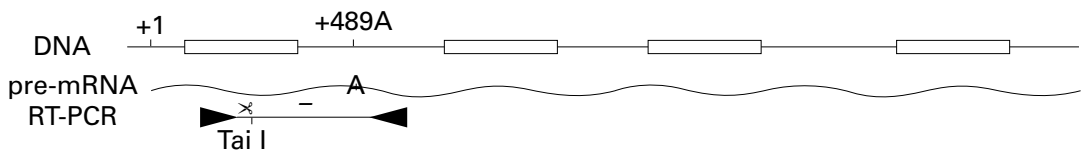

$\mathrm{TNF}+489 \mathrm{G}$
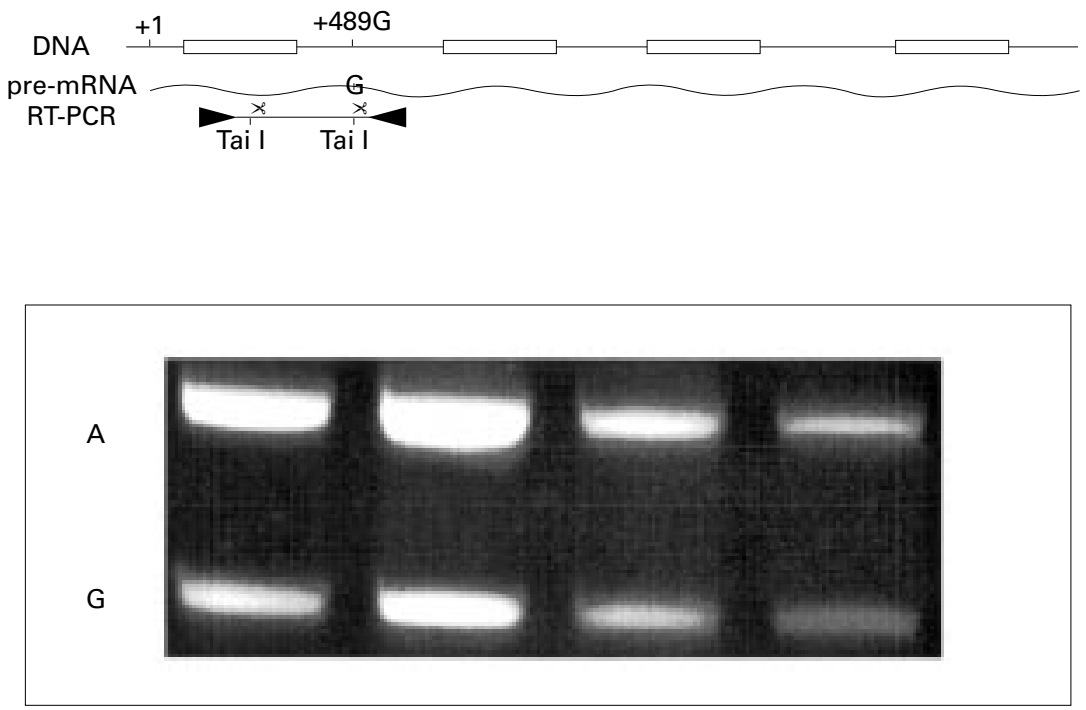

Figure 4 Analysis of the relative contribution of the two +489 alleles in the total TNF precursor mRNA synthesis. Upper panel gives a schematic representation of the genotype of a person heterozygous for the +489 polymorphism. The $G$ at position +489 creates a Tai1 restriction site that is not cleavable in the A allele. PBMC of heterozygous subjects are stimulated with LPS (10 ng/ml) for four hours and RNA is isolated. RNA is reversed transcribed and PCR amplified by two primers spanning the TNF region of interest. Precursor TNF RT-PCR product is digested with Tai to discriminate between the relative contribution of the respective alleles in total TNF precursor production. On the gel results are shown from three people tested. Lane 1; Analysis on genomic DNA from one of the subjects as control (theoretically 1:1), lane 2-4: results from cells stimulated with LPS $10 \mathrm{ng} / \mathrm{ml}$. The A indicates the fragment representing the noncleavable $+489 \mathrm{~A}$ fraction of the transcript. The $G$ the cleavable $+489 G$ fraction.

RA independent of and additive to the HLA SE alleles. Further studies are necessary to determine whether the relevant TNF gene variants contribute directly to the pathophysiology of the disease through distubance of the cytokine haemostasis or is at best a genetic marker of another (unknown) polymorphism in the TNF gene or another immunological relevant gene nearby the TNF locus.

1 Silman AJ, MacGregor AJ, Thomson W, et al. Twin concordance rates for rheumatoid arthritis: results from a nationwide study. J Rheumatol 1993;32:903-7.

2 Lawrence JS. Rheumatoid arthritis nature or norture? Ann Rheum Dis 1970;29:357-79.

3 Aho K, Koskenvuo M, Tuominen J, Kaprio J. Occurrence of rheumatoid arthritis in a nationwide series of twins. J Rheumatol 1986;13:899-902.

4 Cornelis F, Fauré S, Martinez M, et al. Rheumatoid arthritis genome scan and pretative autoimmunity locus. Arthritis Rheum 1997;40:S329.

5 Gregersen PK, Silver J, Winchester RJ. The shared epitope hypothesis: An approach to understanding the molecular hypothesis: An approach to understanding the molecular genetics of susceptibility to

6 Van Zeben, Hazes JMW, Zwinderman AH, et al. Association of HLA-DR4 with a more progressive disease course in patients with rheumatoid arthritis. Arthritis Rheum 1991; 34:822-30

7 Weynand CM, Goronzy JJ. HLA-DRB1 alleles as severity markers in RA. Bull Rheum Dis 1994;43:5-8.

8 Wordsworth P, Bell J. Polygenic susceptibility in rheumatoid arthritis. Ann Rheum Dis 1991;50:343-6.

9 Brennan FM, Maini RN, Feldmann M. TNF alpha-A pivotal role in rheumatoid arthritis. Br J Rheumatol 1992 31:293-8.

10 Elliott MJ, Maini RN, Feldmann M, et al. Treatment of rheumatoid arthritis with chimeric monoclonal antibodies to tumor necrosis factor alpha. Arthritis Rheum 1993;36: 1681-90.

11 Keffer J, Probert L, Cazlaris H, et al. Transgenic mice expressing human tumor necrosis factor: a predictive model of arthritis. EMBO 1991;10:4025-31.

12 Westendorp RGJ, Langermans JAM, Huizinga TWJ, et al. Genetic influence on cytokine production and fatal meningococcal disease. Lancet 1997;349:170-3.
13 Jacob CO, Fronek Z, Lewis GD, et al. Heritable major histocompatibility complex class II-associated differences in production of TNF $\alpha$ : relevance to genetic predisposition to systemic lupus erythematosus. Proc Natl Acad Sci USA 1990;87:1233-7.

14 Bendtzen K, Morling N, Fonsgaard A, et al. Association between HLA-DR2 and production of tumor necrosis factor $\alpha$ and interleukin 1 by mononuclear cells activated by lipopolysaccharide. Scand J Immunol 1988;28:599-606.

15 Pociot F, Briant L, Jongeneel CV, et al. Association of TNF and class II MHC alleles with the secretion of TNF-alpha and TNF-beta by human mononuclear cells: a possible link to insulin-dependent diabetes mellitus. Eur J Immunol 1993;23:224-32.

16 Campbell RD, Trowsdale J, Raquoussis J. Map of the human major histocompatibility complex. Immunol Today 1993;14:349-52.

17 Fernandes DM, Baldwin CL. Interleukin 10 downregulates protective immunity to Brucella abortus. Infect Immun 1995;63:1130-3.

18 Gazznelli RT, Wysocka M, Hieny S, et al. In the absence of endogenous IL-10, mice acutely infected with Toxoplasma gondii succumb to a lethal immune response dependent on CD4+ $\mathrm{T}$ cells and accompanied by overproduction of IL-12, IFNy, and TNFa. J Immunol 1996;157:798-805.

19 Alexander HR, Sheppard BC, Jensen JC, et al. Treatment with recombinat human tumor necrosis factor alpha protects rats against lethality, hypotension, and hypothermia of gram-negative sepsis. J Clin Invest 1991;88:34-9.

20 Rothe J, Lesslauer W, Lotscher $\mathrm{H}$, et al. Mice lacking the tumour necrosis factor receptor I are resistant to TNFmediated toxicity but highly susceptible to infection by $\mathrm{Lis}$ teria monocytogenes. Nature 1993;364:798-802.

21 Kuhn R, Lohler J, Rennick D, Rajewsky K, Muller W. Interleukin-10-deficient mice develop chronic enterocolitis. Cell 1993;75:263-9.

22 Jongeneel CV, Briant L, Udalova IA, et al. Extensive genetic polymorphism in the human tumor necrosis factor region and relation to extended HLA haplotypes. Proc Natl Acad Sci USA 1991;88:9717-21

23 Udalova IA, Nedospasov SA, Webb GC, Chaplin DD, Turetskaya RL. Highly informative typing of the human TNF locus using six adjacent polymorphic markers. Genomics 1993;16:180-6.

24 Messer G, Spengler U, Jung MC, et al. Polymorphic structure of the tumor necrosis factor (TNF) locus: An Ncol polymorphism in the first intron of the human TNF- $\beta$ gene correlates with a variant amino acid in position 26 and a reduced level of TNF- $\beta$ production. J Exp Med 1991;173:209-19. 
25 Partanen J, Koskimies S. Low degree of DNA polymorphism in the HLA-linked lymphotoxin (tumour necrosis phism in the HLA-linked lymphotoxin (tumour nect

26 Ferencir S, Lindemann M, Horsthemke B, Grosse-Wilde H. A new restriction fragment length polymorphism of the human TNF- $\beta$ gene detected by AspHI digest. Eur J Immunogenet 1992;19:425-30.

27 Wilson AG, de Vries N, Pociot F, et al. An allelic polymorphism within the human tumor necrosis factor alpha promotor region is strongly associated with HLA A1, B8 and DR3 alleles. J Exp Med 1993;177:557-60.

28 D'Alfonso S, Richiardi P,M. A polymorphic variation in a putative regulation box of the $\mathrm{TNF} \alpha$ promotor region. Immunogenetics 1994;39:150-4.

29 Brinkman BMN, Kaijzel EL, Huizinga TWJ, et al. Detection of a C-insertion polymorphism within the human tumor necrosis factor alpha (TNFA) gene. Hum Genet 1995;96: necrosis
493 .
Hamman

30 Hamman A, Mantzoros C, Vidal-Puig A, Flier JS. Genetic variability in the $T N F \alpha$-promoter is not associated with variability in the TNF $\alpha$-promoter is not associated with
type II diabetes mellitus (IDDM). Biochem Biophys Res type II diabetes mellitus (IDD
Commun 1995;211:833-9.

31 Uglialoro AM, Turbay D, Pesavento PA, et al. Identification of three new single nucleotide polymorphisms in the human tumor necrosis factor alpha gene promoter. Tissue Antigens 1998;52:359-67.

32 Higuchi T, Seki N, Kamizono S, et al. Polymorphism of the 5 '-flanking region of the human tumor necrosis (TNF) alpha gene in Japanese. Tissue Antigens 1998;51:605-12

33 D'Alfonso S, Momigliano RP. An intragenic polymorphism in the human tumor necrosis factor alpha (TNFA) chain-encoding gene. Immunogenetics 1996;44:321-22.

34 Kaijzel EL, van Krugten MV, Brinkman BMN, et al. Functional analysis of a human tumor necrosis factor alpha promoter polymorphism related to joint damage in rheumatoid arthritis. Mol Med 1998;4:724-33.

35 Miller WL, Morel Y. The molecular genetics of 21hydroxylase deficiency. Ann Rev Genet 1989;23:371-93.

36 Brinkman BMN, Giphart MJ, Verhoef A, et al.Tumor necrosis factor $\alpha-308$ gene variants in relation to major hisnecrosis factor $\alpha-308$ gene variants in relation to major histocompatibility complex alleles

37 McGuire W, Hill AVS, Allsopp CEM, Greenwood BM, Kwiatkowski D. Variation in the TNF $\alpha$ promotor region associated with susceptibility to cerebral malaria. Nature 1994;371:508-12.

38 Cabrera M, Shaw MA, Sharples C, et al. Polymorphism in tumor necrosis factor genes associated with mucocutaneous leishmaniasis. J Exp Med 1995;182:1259-64.

39 Hohler T, Kruger A, Schneider PM, et al. A TNF-alpha promoter polymorphism is associated with juvenile onse psoriasis and psoriatic arthritis. J Invest Dermatol 1997; 109:562-5.
40 Mullighan CG, Fanning GC, Chapel HM, Welsh KI. TNF and lymphotoxin-alpha polymorphisms associated with esis of granulomatous disease. J Immunol 1997;159:623641 .

41 Mulcahy B, Waldronlynch F, Mcdermott MF, et al. Genetic variability in the tumor necrosis factor- lymphotoxin region influences susceptibility to rheumatoid arthritis. Am J Hum Genet 1996;59:676-83.

42 Bali D, Gourley IS, Kostijn D, et al. Genetic analysis of multiplex rheumatoid arthritis families. Arthritis Rheum 1996; 39:S73.

43 Hajeer AH, Worthington J, Silman AJ, Ollier WER. Association of tumor necrosis factor microsatellites polymorphisms with HLA-DRB $1{ }^{\star} 04$-bearing haplotypes in rheumatoid arthritis patients. Arthritis Rheum 1996;39: 1109-14.

44 van Krugten MV, Huizinga TWJ, Kaijzel EL, et al. Association of the TNF +489 polymorphism with susceptibility and radiographic damage in rheumatoid arthritis patients. Genes Immunity (in press).

45 Brinkman BMN, Huizinga TWJ, Kurban SS, et al. Tumour necrosis factor alpha gene polymorphisms in rheumatoid arthritis: association with susceptibility to or severity of, disease? Br J Rheumatol 1997;36:516-21.

46 Criswell LA, Mu H, Such CL, King MC. Tumor necrosis factor (TNF) microsatellite polymorphism is associated with long-term RA outcomes. Arthritis Rheum 1997;9 (suppl):S1787.

47 Brinkman BMN, Zuijdgeest D, Kaijzel EL, Breedveld FC, Verweij CL. Relevance of the tumor necrosis factor alpha (TNF alpha) - 308 promoter polymorphism in TNF alpha gene regulation. J Inflamm 1996;46:32-41.

48 Brinkman BMN, Huizinga TWJ, Breedveld FC, Verweij CL. Allele - specific quantification of TNF $\alpha$ transcripts in rheumatoid arthritis. Hum Genet 1996;97:813-18.

49 Stuber F, Udalova IA, Book M, et al. -308 tumor necrosis factor (TNF) polymorphism is not associated with survival in severe sepsis and is unrelated to lipopolysaccharide inducibility of the human TNF promoter. J Inflamm 1996; 46:42-50.

50 Wilson AG, Symons JA, McDowell TL, McDevitt HO, Duff GW. Effects of a polymorphism in the human tumor necrosis factor alpha promoter on transcriptional activation. Proc Natl Acad Sci USA 1997,94:3195-9.

51 Kroeger KM, Carville KS, Abraham LJ. The -308 tumor necrosis factor promoter polymorphism effects transcription. Mol Immunol 1997;34:391-9.

52 Braun N, Michel U, Ernst BP, et al. Gene polymorphism at position -308 of the tumor necrosis factor alpha (TNFalpha) gene in multiple sclerosis and its influence on the regulation of TNF alpha production. Neurosci Lett $1996 ; 215: 75-8$. 